\title{
STUDI HUBUNGAN ANTARA SENAM NIFAS, INSIASI MENYUSU DINI (IMD) DAN PARITAS DENGAN INVOLUSIO UTERI
}

\author{
Study Of Relationship Between Senam Nifas, Early Breastfeeding Initiation (IMD) \\ And Parity With Uteri Involution
}

\author{
Sholaikhah Sulistyoningtyas \\ Universitas 'Aisyiyah Yogyakarta \\ Sholaikhahtyas@Unisayogya.ac.id
}

\begin{abstract}
ABSTRAK
Berdasarkan hasil Survei Demografi dan Kesehatan Indonesia (SDKI) tahun 2012, angka kematian ibu di Indonesia di masih tinggi sebesar 359 per 100.000 kelahiran hidup. Faktor-faktor yang menyebabkan kematian ibu di Indonesia ada barbagai macam, perdarahan dan infeksi menempati posisi tertinggi penyebab kematian ibu. Masing-masing memiliki prosentase 28\% dan 11\% (Kepmenkes RI,2014). Salah satu factor yang menyebabkan perdarahan adalah atonia uteri dikarenkan adanya subinvolusi uteri . factor yang mempengaruhi proses involusio uteri ada beberapal diantaranya paritas,senam nifasdan IMD Tujuan penelitian ini untuk mengetahui hubungan senam nifas, paritas dan pelaksanaan Inisiasi Menyusu Dini (IMD) terhadap proses involusi uteri pada ibu postpartum di Klinik Pratama Istri Utami Sleman. Penelitian ini menggunakan metode kuantitatif dengan pendekatan waktu retrospektif menggunakan uji kolerasi analisis Chi-Square. Analisis data univariat dan bivariat menggunakan data rekam medis. Jumlah sampel diambil dengan teknik sistematik random sampling sebanyak 56 responden ibu postpartum.. Hasil statistik menggunakan uji chi square untuk hubungan senam nifas dengan involusi uteri nilai $p$ value $(0,000<0,05)$ antara paritas ibu dengan involusi uteri $p$ value $(0,000<0,05)$ dan untuk IMD $p$ value $(0,000<0,05)$. Kesimpulannya ada hubungan senam nifas, paritas ibu dan Inisiasi Menyusu Dini (IMD) dengan involusi uteri di Klinik Pratama Istri Utami. Saran bagi Kliinik Pratama Istri Utami untuk tetap menjaga dan meningkatkan kualitas pelayanan terhapat KIA dengan update ilmu terbaru.
\end{abstract}

Kata Kunci: Senam NIfas, Paritas IMD dan Involusio Uteri

\begin{abstract}
Based on the results of the 2012 Indonesian Demographic and Health Survey (IDHS), the maternal mortality rate in Indonesia is still high at 359 per 100,000 live births. The factors that cause maternal mortality in Indonesia are various kinds, bleeded and infection occupy the highest position for the cause of maternal death. Each has a percentage of $28 \%$ and $11 \%$ (Kepmenkes RI, 2014). One factor that causes bleeding is uterine atony due to uterine subinvolution. There are several factors that influence the involuntary uterine process, including parity, puerperal gymnastics and IMD. The purpose of this study was to determine postpartum gymnastic relationship, parity and the implementation of Early Breastfeeding Initiation (IMD) for uterine involution in postpartum mothers at Pratama Klinik Istri Utami Sleman. This study uses a quantitative method with a retrospective time approach using the Chi-Square analysis of correlation test. Univariate and bivariate data analysis using medical record data. The number of samples was taken with a random sampling systematic technique as many as 56 postpartum mothers. Statistical results using chi square test for puerperal gymnastics with uterine involution $\mathrm{p}$ value $(0,000<0,05)$ between maternal parity with uterine involution $\mathrm{p}$ value $(0,000<0,05)$ and for IMD $\mathrm{p}$ value $(0,000<0,05)$. In conclusion there are postpartum gymnastic relations, maternal parity and Early Breastfeeding Initiation (IMD) with uterine involution at the Primary Clinic of the Utami Wife. Suggestions for Kliinik Pratama Istri Utami to keep maintaining and improving the quality of services available to KIA with the latest science updates.
\end{abstract}

Keywords : Nifas Gymnastics, IMD, Parity and Uterine Involution 


\section{PENDAHULUAN}

Berdasarkan hasil Survei Demografi dan Kesehatan Indonesia (SDKI) tahun 2012, angka kematian ibu di Indonesia di masih tinggi sebesar 359 per 100.000 kelahiran hidup. Faktor-faktor yang menyebabkan kematian ibu di Indonesia ada barbagai macam, perdarahan dan infeksi menempati posisi tertinggi penyebab kematian ibu. Masing-masing memiliki prosentase $28 \%$ dan $11 \%$ (Kepmenkes RI,2014). Penyebab dari perdarahan pasca persalinan antara lain atonia uteri $(50-60 \%)$ yang disebabkan proses persalinan yang lama, retensio plasenta (1617\%) yang disebebkan karena implantasi plasenta yang lama didalam dinding rahim sehingga involusio terhambat, retensio sisa plasenta (23-24\% karena ada selaput yang tertinggal didalam uterus, laserasi jalan lahir (4-5\%) karena robekan jalan lahir yang lebar serta karena kelainan pembekuan darah (Moedjiarto, 2011).

Menurut Depkes RI diperkirakan 14 juta kasus perdarahan dalam setiap tahunnya dan paling sedikit 128.000 wanita mengalami perdarahan sampai meninggal. Di Indonesia, dari 170.725 ibu bersalin terdapat 8.212 kasus $(4,1 \%)$ ibu yang mengalami perdarahan (Depkes RI, 2008). Angka Kematian Ibu karena perdarahan post partum mempunyai peringkat tertinggi dimana salah satu penyebab perdarahannya adalah atonia uteri.

Bila uterus pada ibu post partum mengalami kegagalan dapat menyebabkan subinvolusio yang sering disebabkan oleh infeksi dan tertinggalnya sisa plasenta dalam uterus sehingga proses involusi uterus tidak berjalan normal atau terhambat. Bila uterus pada ibu post partum mengalami kegagalan dapat menyebabkan sesuatu yang disebut subinvolusio yang sering disebabkan oleh infeksi dan tertinggalnya sisa plasenta dalam uterus sehingga proses involusi uterus tidak berjalan normal atau terhambat. Bila sub involusio tidak tertangani akan menyebabkan perdarahan yang berlanjut atau postpartum haemorrhage hingga kematian. Baik di negara maju maupun negara berkembang, perhatian utama bagi ibu dan bayi terlalu banyak tertuju pada masa kehamilan dan persalinan, sementara keadaan yang sebenarnya justru merupakan kebalikannya, oleh karena resiko kesakitan dan kematian ibu serta bayi lebih sering terjadi pada masa pasca persalinan (Saifuddin, 2009). Percepatan involusi uteri dipengaruhi oleh beberapa faktor antara lain, usia ibu, paritas, menyusui eksklusif, mobilisasi dini dan inisiasi menyusui dini (IMD). Faktor umur, pada umur dibawah 20 tahun elastisitas otot uterus belum maksimal, sedangkan pada usia diatas 35 tahun elastisitas otot berkurang. Status gizi yang baik akan mampu menghindari serangan kuman sehingga tidak terjadi infeksi dalam masa nifas dan mempercepat involusi uterus (Mayasari,dkk, 2015).

Senam nifas adalah latihan gerak yang dilakukan secepat mungkin setelah melahirkan, supaya otot-otot yang mengalami peregangan selama kehamilan dan persalinan dapat kembali kepada kondisi normal seperti semula (Sukaryati dan Maryunani, 2011). senam nifas merupakan latihan jasmani yang berfungsi untuk mengembalikan kondisi kesehatan, umuk mempercepat penyembuhan, mencegah timbulnya komplikasi, memulihkan dan memperbaiki regangan pada otot-otot setelah kehamilan, terutama pada otot-otot bagian punggung, dasar panggul, dan perut.

Paritas adalah jumlah kehamilan yang menghasilkan janin yang mampu hidup diluar Rahim (28 mggu) (JHPIEGO, 200(2008). Sedangkan menurut manuaba (2008), paritas adalah wanita yang pernah melahirkan bayi aterm. Menurut Prawirohardjo (2009) paritas dapat dibedakan menjadi primipara dan multipara dan grande multipara. Semakin tinggi paritas maka secara fisiologis akan semakin fungsi reproduksi mengalami penurunan, otot uterus terlalu regang dan kurang dapat berkontraksi dengan baik sehingga kemungkinan proses involusi uterus akan berkurang. (Manuaba,2008)

\section{METODE}

Jenis penelitian ini adalah studi korelasi yaitu penelitian antara dua variabel pada situsi atau suatu kelompok subyek (Notoadmojo, 2010).. Metode pendekatan retrospektif, dengan menggunakan variable bebas meliputi senam nifas, paritas dan IMD, dan variable terikat adalah involusi uteri. Sampel dalam penelitian ini adalah ibu nifas dengan jumlah sampel 56 responden. Analisi dalam penelitian ini dengan menggunakan $c h i$ square untuk mengetahui hubungan antara variable bebas dan variable terikat. 
HASIL

Hubungan Senam NIfas, Paritas dan IMD dengan Involusio Uteri di KLinik Pratama Istri Utami.

Tabel 4. 4 Hubungan senam nifas, paritas dan Involusio Uteri di KLinik Pratama Istri Utami.

\begin{tabular}{|c|c|c|c|c|c|}
\hline \multirow{3}{*}{$\begin{array}{l}\text { Involusi } \\
\text { uteri } \\
\text { Paritas }\end{array}$} & \multicolumn{4}{|c|}{ Involusi } & \multirow{3}{*}{$\begin{array}{l}\text { P value } \\
\\
\text { Coef } \\
\text { Conting } \\
\text { ency }\end{array}$} \\
\hline & \multicolumn{2}{|c|}{ Normal } & \multicolumn{2}{|c|}{$\begin{array}{c}\text { Tidak } \\
\text { Normal }\end{array}$} & \\
\hline & $\mathrm{N}$ & $\%$ & $\mathrm{~N}$ & $\%$ & \\
\hline $\begin{array}{l}\text { Tidak } \\
\text { Beresiko }\end{array}$ & 34 & 61 & 9 & 16 & 0.000 \\
\hline Beresiko & 3 & 5 & 10 & 18 & 0,507 \\
\hline $\begin{array}{l}\text { Senam } \\
\text { Nifas }\end{array}$ & & & & & \\
\hline$-\mathrm{Ya}$ & 31 & 55 & 7 & 13 & 0.000 \\
\hline - Tidak & 6 & 11 & 12 & 21 & 0,430 \\
\hline IMD & & & & & \\
\hline$-\mathrm{Ya}$ & 33 & 59 & 6 & 11 & 0.000 \\
\hline - Tidak & 4 & 7 & 13 & 23 & 0,510 \\
\hline
\end{tabular}

Dari tabel 4.4 dapat diketahui bahwa dari untuk variable paritas : untuk paritas yang tidak beresiko dan involusi uteri normal terdapat 34 responden (61\%). Dan yang paritas tidak beresiko dan involusio uterinya tidak normal adal 9 responden (16\%). Kemudian untuk yang paritas beresiko dan involusio normal ada 3 responden atau sebanyak $(5 \%)$ sedangkan yang paritas beresiko dan involusio tidak normal terdapat 10 responden atau sebanyak (18\%). Variable bebas senam nifas, untuk responden yang melakukan senam nifas dan involusio normal terdapat 31 reponden atau sebanyak (55\%). Responden yang melakukan senam hamil dan involusionya tidak normal ada 7 responden atau sebanyak (13\%). Responden yang tidak melakukan senam nifas dan terjadi involusi normal ada 6 responden atau sebanyak (11\%). Sedangkan untuk responden yang tidak melakukan senam nifas dan involusi tidak normal ada 12 responden atau sebanyak (21\%).

Variable IMD, untuk responden yang dilakukan IMD dan involusi normal terdapat 33 responden atau sebanyak (59\%), responden yang dilakukan IMD dan involusi tidak normal ada 6 responden atau sebanyak (11\%). Sedangkan untuk responden yang tidak dilakukan IMD dan involusi normal ada 4 orang atau sebanyak (7\%), dan yang tidak dilakukan IMD dan involusi tidak normal adal 13 responden atau sebanyak $(23 \%)$.

\section{PEMBAHASAN}

a. Hubungan Senam Nifas dengan involusio Uteri di Klinik Pratama Istri Utami.

Dari Hasil penelitian tentang senam nifas didapatkan hasil bahwa nilai $\mathrm{p}$ value sebesar 0,000 yang berarti nilai $p$ value lebih kecil dari nilai signifikansi 0.05 yang menunjukkan Ha : ditolak dan Ho diterima dari hasil penelitian dapat simpulkan bahwa terdapat hubungan yang signifikan antara senam nifas dengan involusi uteri di Klinik Pratama Istri Utami.

Hasil penelitian pada ibu post partum, untuk responden yang melakukan senam nifas dan involusio normal terdapat 31 reponden atau sebanyak (55\%). Responden yang melakukan senam hamil dan involusionya tidak normal ada 7 responden atau sebanyak (13\%). Responden yang tidak melakukan senam nifas dan terjadi involusi normal ada 6 responden atau sebanyak (11\%). Sedangkan untuk responden yang tidak melakukan senam nifas dan involusi tidak normal ada 12 responden atau sebanyak (21\%). Dari hasil diatas masih terdapat 7 ibu post partum yang melakukan senam nifas tetapi involusio uteri tidak normal hal ini bisa terjadi karena factor lain yang mempengaruhi salah satunya adalah senam yang dilakukan kurang maksimal.

Menurut Sjaharudin (2006) dalam penelitian sjaflindawati 2016 mengatakan Salah satu cara untuk mempercepat involusi uterus yaitu dengan melakukan senam nifas yang bertujuan merangsang otot-otot rahim agar berfungsi secara optimal sehingga diharapkan tidak terjadi perdarahan post partum dan mengembalikan rahim pada posisi semula. Manfaat senam nifas adalah memulihkan kembali kekuatan otot dasar panggul, mengencangkan otot-otot dinding perut dan perineum, membentuk sikap tubuh yang baik dan mencegah terjadinya komplikasi. Komplikasi yang dapat dicegah sedini mungkin dengan melaksanakan senam nifas adalah perdarahan post partum.

Saat melaksanakan senam nifas terjadi kontraksi otot-otot perut yang akan membantu proses involusi. Pada kenyataannya banyak ibu nifas yang tidak 
melakukan senam nifas karena ada tiga alasan. Pertama, karena tidak tahu bagaimana senam nifas. Kedua, karena terlalu bahagia dan yang dipikirkan hanya si kecil. Ketiga, karena alasan sakit. Senam nifas sebaiknya dilakukan dalam waktu 24 jam setelah melahirkan, secara teratur setiap hari. Setelah 6 jam persalinan normal atau 8 jam setelah operasi sesar, ibu sudah boleh melakukan mobilisasi dini, termasuk senam nifas. Melakukan senam nifas akan mempengaruhi kebutuhan otot terhadap oksigen yang mana kebutuhan akan meningkat, berarti memerlukan aliran darah yang kuat seperti otot rahim. Dengan dilakukan senam nifas akan merangsang kontraksi rahim, sehingga kontraksi uterus akan semakin baik, pengeluaran lokia akan lancar yang akan berpengaruh terhadap proses involusi rahim (syaflindawati, 2016).

b. Hubungan Paritas Dengan Involusio Uteri di Klinik Pratama Istri Utami

Dari hasil penelitian didapatkan hasil dari 43 responden yang paritas tidak beresiko terdapat $34(61 \%)$ ibu mengalami involusio normal dan ada 9 responden (16\% )yang involusio tidak normal. Hal ini disebabkan karena involusi uteri tidak hanya dipengaruhi oleh paritas saja tetapi ada juga faktor yang dapat mempengaruhi involusi uteri yaitu senam nifas dan mobilisasi dini, dimana faktor- faktor tersebut tidak dikendalikan oleh peneliti.

Berdasarkan teori Manuaba (2008) secara fisilogis paritas menyebabkan ketidaksiapan ibu dalam menghadapi persalinan sehingga ibu hamil tidak mampu dalam menangani komplikasi yang terjadi selama kehamilan, persalinan dan nifas, fungsi reproduksi mengalami penurunan, otot uterus terlalu regang dan kurang dapat berkontraksi dengan baik sehingga kemungkinan terjadi perdarahan pascapersalinan menjadi lebih besar (Manuaba, 2008).

Hasil penelitian ini mendukung penelitian Apriliasari (2010) hubungan usia dan paritas dengan kejadian involusi ibu nifas. Hasil penelitiannya menunjukan sebagian besar paritas responden 2-4 (multipara) sebanyak 12 responden (60\%), hampir setengah dari responden mengalami involusi tidak normal sebanyak 7 responden (35\%). Hasil analisis menggunakan uji rank spearman dengan didapatkan $\mathrm{p}$ value $=$ $0,007<0,05$ yang artinya ada pengaruh usia terhadap involusi uteri. Serta hasil penelitian rina purnamasari (2017). Hasil penelitian menunjukan dari 54 ibu nifas yang melahirkan secara pervaginam 16 orang $(50,0 \%)$ paritas multipara (2-4) mengalami involusi uteri tidak normal dengan analisi uji spearman rank didapatkan nilai $\mathrm{p}=0,019<0,05$ dinyatakan ada hubungan paritas dengan involusi uteri. Dan sejalan juga dengan penelitian Ferdina, 2014, hasil penelitiannya menunjukan sebagaian besar responden termasuk dalam kategori primi $(66,7 \%)$ dan involusi uteri didapatkan normal $(56,7 \%)$.

Hasil ini berbanding terbalik dengan penelitan Yusro Hadi (2014) hubungan paritas ibu dengan involusi uterus pada hari ke 20, diketahui dari 17 orang berparitas berisiko terdapat $5(25 \%)$ ibu yang tinggi fundus uterus setelah hari ke10 masih teraba (belum kembali), sedangkan dari 29 ibu dengan paritas tidak berisiko ada 9 $(31,0 \%)$ ibu yang fundus uterus masih teraba pada hari ke 20. Hasil uji statistic hubungan antara paritas ibu dengan kembalinya uterus didapatkan $\mathrm{p}$ value 1,000 , artinya tidak ada hubungan antara paritas ibu dengan kejadian kembalinya uterus ibu postpartum. Dan penelitian Tri Godha Fhhitriani ( 2013) hubungan paritas dan usia ibu bersalin dengan hasil paritas resiko sebanyak 10 ibu dan yang tidak resiko sebanyak 25. Hasil tabulasi silang diketahui paritas tidak resiko lebih besar terjadi involusi tidak normal sebanyak 25 orang (26,1\%). Hasil ini berbanding terbalik dimungkinan karena dipengaruhi beberapa faktor lain seperti mobilisasi dini dan senam nifas yang dapat mempengaruhi proses involusi uteri tetapi tidak tertulis lengkap di rekam medis.

c. Hubungan IMD dengan Involusi Uteri di Klinik Pratama Istri Utami.

Berdasarkan hasil penelitian yang dilakukan terhadap 56 responden menunjukan bahwa ibu yang melakukan IMD mengalami involusi uteri normal yaitu sebanyak 33 responden (59\%), dan 6 (11 $\%$ ) responden dengan ibu yang melakukan IMD dengan involusi tidak normal. Dan dari hasil ibu yang tidak melakukan IMD dan mengalami involusi uteri normal yaitu 
sebanyak 4 responden (7\%) sedangkan yang tidak melakukan IMD dan mengalami involusi tidak normal sebanyak 13 (23\%) responden. Hasil analisis menggunakan uji chi square $\mathrm{p}$ value $=0,05$ didapatkan bahwa p $0,000<0,05$ yang artinya ada hubungan IMDdengan involusi uteri di Klinik Pratama Istri Utamil. Hal ini berhubungan dikaarenakan saat menyusui akan terjadi kontak kulit antara ibu dan bayi. Ketika kontak fisik ibu dan bayi tetap dipertahankan setelah bayi lahir, konsentrasi perifer oksitosin dalam sirkulasi maternal menjadi tinggi dalam 1 jam pertama dibanding sebelum lahir. Intensitas kontraksi uterus akan meningkat setelah bayi lahir hal ini terjadi karena adanya respon terhadap penurunan volume intrauterine yang sangat besar.

Hasil penelitian ini sejalan dengan beberapa penelitian diantaranya Agustina dkk (2016) dengan Hasil uji statistik menggunakan uji chi-square didapat $\mathrm{P}$ Value $0,005<0,05$ yang berarti adanya hubungan antara IMD dengan Involusi uteri. Sejalan dengan pendapat Manuaba IBG (2010) IMD atau Menyusui dini merupakan salah satu faktor pendukung proses involusi uteri dikarenakan dengan memberikan ASI kepada bayi pada satu jam pertama, memberi efek kontraksi pada otot polos uterus disebabkan karena adanya kontak kulit ke kulit yang terjadi. Ketika terjadinya skin to skin meningkatkan konsentrasi perifer oksitosin dalam sirkulasi maternal tampaknya menjadi tinggi dalam satu jam pertama dibanding sesaat sebelum lahir. Hal inilah yang membantu mempercepat proses involusi uterus. Efek hormon oksitosin secara bersamaan memacu sel-sel myometrium pada uterus sehingga membantu pengeluaran plasenta dan mengurangi terjadinya perdarahan postpartum.

Penelitian ini juga sejalan dengan penelitian Apriyani ( 2016) yang menunjukkan hasil menggunakan analisis chi square dengan nilai signifikansi $\mathrm{p}$ $0,012<0,05$. Yang menunjukkan terdapat hubungan antara IMD dengan involusi uteri di RS PKU Muhammadiyah Bantul..

Hal ini juga sejalan dengan teori manuaba (2011 ) yang mengatakan Oksitosin merupakan zat yang dapat merangsang myometrium sehingga dapat berkontraksi. Kontraksi uterus merupakan suatu proses yang kompleks dan terjadi adanya pertemuan aktin dan myosin. Pertemuan aktin dan myosin disebabkan karena adanya myocin light chine kinase (MLCK) dan dependent myosin ATP ase, proses ini dapat dipercepat oleh banyaknya ion kalsium yang masuk ke dalam sel, sedangkan oksitosin merupakan salah satu hormon yang memperbanyak masuknya ion kalsium kedalam intra sel. Sehingga adanya oksitosin akan memperkuat kontraksi uterus.

IMD juga merupkan salah satu faktor yang memengaruhi proses terjadinya involusi uterus. Saat dilkakukan IMD adanya pelepasan oksitosin pada saat puting susu ibu diisap oleh bayi. Kontraksi mioepitel sekeliling duktus laktiferus dengan pengaruh oksitosin menyebabkan kontraksi rahim yang membantu lepasnya plasenta dan mengurangi perdarahan. Oleh karena itu, setelah dilahirkan jika memungkinkan bayi perlu segera disusukan ibunya IMD agar merangsang kontraksi pada uterus.

Kontraksi dan retraksi otot uterus akan membantu proses involusi uteri dan mengurangi perdarahan. Selama 1 sampai 2 jam pertama postpartum intensitas kontraksi uterus bisa berkurang dan menjadi teratur, karena itu sangat penting sekali menjaga dan mempertahankan kontraksi uterus pada masa ini. Pemberian ASI segera setelah bayi lahir akan merangsang pelepasan uterus pada oksitosin karena hisapan bayi pada pada payudara. Pada ibu yang melakukan IMD, hisapan bayi pada puting ibu akan merangsang oksitosin dan membantu uteru kembali ke bentuk normal serta merangsang pengeluaran air susu (Ambarwati, 2010). Menurut Sagita (2011) IMD merupakan salah satu faktor yang mendukung untuk terjadinya proses involusi uteri, karena dengan memberikan ASI segera setelah bayi lahir memberikan efek kontraksi pada otot polos uterus

\section{KESIMPULAN}

Dari hasil penelitian didapatkan kesimpulan bahwa :

a. Sebagian besar ibu post partum di Klinik Pratam Istri Utami melakukan senam nifas sebanyak 38 responden $(67 \%)$ 
b. Sebagian besar paritas ibu post partum tergolong paritas tidak beresiko di Klinik Pratama Istri Utami sebanyak 43 responden $(77 \%)$

c. Sebagian ibu post partum di Klinik Pratama Istri Utami melakukan IMD sebanyak 39 responden $(70 \%)$

d. Terdapat hubungan antara senam nifas dengan involusi uteri di klinik Pratama Istri Utama dengan nilai $p$ Value 0,000

e. Terdapat hubungan antara paritas dengan involusio uteri di Klinik Pratama Istri Utama dengan nilai $P$ value 0,000

f. Terdapat hubungan antara IMD dengan involusio uteri di Klinik Pratama Istri Utami dengan nilai $P$ value 0,000

\section{SARAN}

1. Bagi Bidan

Diharapkan dari hasil penenlitian ini bagi tenaga bidan khususnya dapat menerapkan senam nifas dan inisiasi menyusu dini (IMD) pada ibu postpartum. Untuk mengurangi faktor resiko terjadinya subinvolusi dan melakukan skrening kehamilan agar persalinannya tidak beresiko diantara nya menjaga paritas ibu..

2. Bagi ibu nifas

Diharapkan dari hasil penelitian ini ibu nifas lebih memprogram dan mengantisipasi lebih awal untuk kehamilan selanjutnya guna mencegah terjadinan perdarahan postpartum.

3. Bagi Klinik Pratama Istri Utami.

Diharapkan dapat menjaga dan meningkatkan kualitas pelayanan pada Ibu dan Anak serta terus meningkatkan updateupdate ilmu terbaru.

\section{DAFTAR PUSTAKA}

Aghdas, K., Talat ,K., dan Sepideh,B. (2014). Effect of immediate and continous mother-infant skin to skin contact on breastfeeding self-efficacy of primiparus women : A random control trial. Women and Birth. 27 (1),37-40

Anggraini, Y dan Martini. (2012). Asuhan Kebidanan Masa nifas. Yogyakarta: Pustaka Rihama

Ambarwati, E,R,Diah, W. (2010). Asuhan Kebidanan Nifas. Yogyakarta: Nuha Medika.
Apriyani . 2017. Hubungan umur ibu dan IMD denagn involusi uteri. Universitas Aisyiyah Yogyakarta tahun 2017.

Arikunto S. (2010). Metodologi Penelitian. Jakarta: Rineka Cipta

Depkes RI. (2013). Profil Kesehatan Republik Indonesia Tahun 2013 dalam https://www.google.co.id/url?sa=t\& $\mathrm{rct}=\mathrm{j} \& \mathrm{q}=\&$ esrc $=\mathrm{s} \&$ source $=$ web $\& \mathrm{~cd}$ $=1 \& \mathrm{cad}=\mathrm{rja} \&$ uact $=8 \& \mathrm{ved}=0 \mathrm{ahUK}$ EwiOt8fJkabVAhXFkpQKHcO_B qAQFggmMAA\&url=http $\% 3 \mathrm{~A} \% 2$ F\%2Fwww.depkes.go.id\%2Fresour ces $\% 2$ Fdownlod $\% 2$ Fpusdatin $\% 2 \mathrm{Fp}$ rofil-kesehatanindonesia\%2Fprofil-kesehatan indonesia2013.pdf\&usg=AFQjCNEuo4ufQn GeUaGa7FN1Gi2HkMFLuA diakses 19 Januari 2017

Dwi Apriliasari. (2015). Hubungan Usia Dan Paritas Dengan Kejadian Involusi Ibu Nifas Di Bps Mojokerto. Jurnal Ilmiah Kebidanan, Vol. 5 No. 1 Edisi Agustus 2015

Friske Wulan. (2010). Pengaruh Menyusui Terhadap Penurunan Tinggi Fundus Uteri Pada Ibu Post Partum Primigravida Di Rsud Dr. R. Sosodoro Djatikoesoemo Bojonegoro. Lembaga Penelitian Dan Pengabdian Masyarakat Akes Rajekwesi Bojonegoro, Vol.1, No.1, Edisi Desember 2010

JNPK-KR. (2008). Asuhan Kebidanan Ibu Nifas. Jakarta : JPIEGO

Marmi.(2012). Asuhan Kebidanan Patologi. Yogyakarta : Pustaka Belajar

Martini. (2012). Hubungan Inisiasi Menyusu Dini Dengan Tinggi Fundus Uteri Ibu PostPartum Hari ke tujuh di Wilayah Kerja Puskesmas Kotabumi II Lampung utara. Tesis : Fakultas Ilmu Kesehatan Masyarakat Universitas Indonesia 
Fitriana M, Meikawati W, dkk. (2014). Faktor-Faktor Yang Mempengaruhi Involusi Uterus (Studi Kasus Di Bpm Ida Royani Dan Bpm Sri Pilih Retno Tahun 2014). Fakultas Kesehatan Masyarakat Universitas Muhammadiyah Semarang Vol 5 No 2 edisi April 2014 